\title{
EVIDENCE OF TEXTURAL AND CHEMICAL EVOLUTIVE PATHS BY MEANS OF IMAGE PROCESSING IN WEATHERING AND DIAGENETIC PROCESSES
}

\author{
PARRON C.*, SIMON B.*,**, OLTRA P.H.** and COLIN F. * \\ * Laboratoire de Géosciences de l'Environnement, URA CNRS 132, Université Aix-Marseille III , \\ 13397 Marseille Cedex 13, France. \\ ** Service de Télédétection et de Sciences de l'image (STSI), Université Aix-Marseille III, \\ 13397 Marseille Cedex 13, France.
}

\section{I - INTRODUCTION}

Both the texture and the chemical composition of rocks and minerals change when affected by low-rate weathering and/or by diagenetic processes. Such changes cannot be accurately defined because the detailed study is impossible by means of classical methods such as optical microscopy or more simply by naked eye. Nevertheless, these changes in texture and in chemical composition reflect the changes of the organization of the matter and thus are good pathfinders to the genesis, and the development of both the weathering and the diagenetic processes. The purpose of this work is to performe a statistical and mathematical algorithm to analyse chemical and textural information from geologic samples.

\section{II- METHOD}

The studied samples are glauconite grains and gold particles ranging in size from a few microns to a millimeter. The starting images are obtained by optical or electron microscope. The mathematical treatment of these images is based on the co-occurence matrix theory, applied to the grey levels of the images, from which it is possible to calculate the contrast, the anisotropy and the entropy (Oltra, 1988). The contrast parameter allows, for a given digitized image, determination of the texture classification, and cartography of textural anisotropies. The images of minerals are obtained from thin sections by a camera through an optical microscope under transmitted light. The mappings of chemical elements are obtained from polished thin sections by microprobe analysis. The images of these mappings are obtained by a camera under reflected light. This camera is interfaced with a pericolor Numelec 2000 system, generating $256 \times 256$ pixel images. The treatment of the digitized images is complemented with a 4381-12 IBM computer.

\section{III - APPLICATIONS}

I - Textural anisotropy study of glauconite grains : Evidence of glauconitization process.

A study of crystallochemical and structural mechanisms involved in the genesis of glauconite minerals has been carried out on glauconite-rich rocks from the Paleocene series of the Ivory Coast (Parron, 1989). Unusual glauconite grains show well rounded shapes, internal spherolitic structure and have a diameter ranging from a few microns to 200 microns. Within a given sample, at the scale of the thin section, those grains occur with larger grains ( 500 to 700 microns), charaterized by ovoid and botryoidal shapes and unspherolic structwes. In addition, the smaller grains have a darker green color and a higher amount of $\mathrm{K}_{2} \mathrm{O}$ than the larger ones. Such features indicate that the smaller grains result from a more evolved stage of glauconitization (Parron, 1989). The image processing has been carried out on transitional series of grains, in order to draw a parallele between the glauconitization process and the textural changes of the grains. The result demonstrate that all the grains show a textural heterogeneity. Within a given grain, several domains occur, characterized by a decreasing anisotropy from the core to the rim of each domain. The textural 
heterogeneity is correlated to the number of textural domains. This number decreases from the larger ovoid grains (7), to the botryoidal grains ( 3 to 5) and then to the small rounded grains (1). From ovoid to botryoidal grains, the domains of textural anisotropy coincide with protuberances of the botryoidal morphology of the grains. Those protuberances seem to be protograins for the small rounded grains. As a result, the evolution of both the color and the chemical composition of the grains during the glauconitization process simultaneously evolve with size, morphology and internal texture of such grains. The end-members of this evolution by glauconitization process are the smaller grains characterized by rounded shape and textural homogeneity. These grains result from an in situ division of the larger ones.

This result contrasts with those previously reported in the literature which suggests that the smaller spheroidal grains originate from the larger ones by physical abrasion (Boyer, 1977) or generate botryoidal grains by packing (Triplehorn, 1966).

\section{2- Study of chemical evolution by image processing from mappings.}

a) Evidence of glauconitization process

The mappings of the main chemical elements ( $\mathrm{Si}$, $\mathrm{Fe}, \mathrm{K}$ ) have been obtained from the same grains which were examined above. The chemical changes vary in a narrow scale and the information extracted from these mappings is difficult to interprete by naked eye. On the other hand, image processing improves the mappings and give detailed chemical maps, which can be compared to the textural maps previously examined. Thus, the results evidence a chemical heterogeneity evolving at the same time as the textural heterogeity. Within the grains, the central zones showing a minimal textural anisotropy correspond to the zones where the concentrations of $\mathrm{Si}, \mathrm{Fe}, \mathrm{K}$ are the highest. From these zones, the concentrations of $\mathrm{Si}, \mathrm{Fe}, \mathrm{K}$ decrease toward the rims of the grains. The transformation of the large ovoid grains into the small rounded ones can be interpreted as a progressive chemical homogeneization process. The textural differentiation is also chemical.

b) Evidence of weathering of gold particles

Morphological and chemical studies have been carried out on gold particles which have been extracted from weathering profiles developed under equatorial lateritic conditions (Colin et al., 1989 a, b). The increasing weathering of the gold particles from the protore upward the soils induces reduced sizes, rounded shapes and preferential leaching of silver. To study in details how silver distribution evolves within gold particles during weathering, microprobe analysis mapping has been performed on 21 gold particles. As the silver concentrations are below 9 percent, the mappings are difficult to interprete. To improve the mappings, image processing has been used. About the fresh particles, the results demonstrate that the silver distribution is homogeneous and undependant of the shape of the particles.

This results contrasts with those obtained for the weathered particles. In addition, the preferential leaching of silver, which takes place in the weathered particles, develops either from the rims of the particles or from the intergranular limits inside the particles. The heterogeneity of the silver distribution within gold particles progressively increases from the protore to the surface.

\section{IV - CONCLUSIONS}

Two new methods of image processing have been perfected and carried out on rock and mineral samples, which result from low-rate textural and chemical transformations under surficial conditions.

The maps of textural anisotropy demonstrate textural changes which are not visible by classical technics. Such maps consitute helpful tools for qualitative and quantitative studies. The maps of distribution of chemical elements allow to perfect the chemical data obtained by microprobe analysis, especially when the concentrations of chemical elements are low.

These methods can be applied on rocks and minerals at the micrometer scale (this study) and also at the nanometer scale required by high resolution transmission electron microscopy.

\section{REFERENCES}

BOYER P.S., GUINNESS E.A., LYNCH-BLOSSE M.A. and STOLZMAN R.A. (1977). J. Sed. Petr., 47, p. 267-280. COLIN F., EDOU MINKO A. and NAHON D. (1989 a). C. R. Acad. Sci. Paris, 309, p. 553-560.

COLIN F., SIMON B., OLTRA P.H. and PARRON C. (1989 b). "Gold 89 in Europe", Terra Abstracts, 1, p. 32.

OLTRA P.H. (1988). Thesis Doct. Ing., Aix-Marseille III Univ., $159 \mathrm{p}$.

PARRON (1989). Thesis Doct. ès Sci., Aix-Marseille III Univ., $411 \mathrm{p}$.

TRIPLEHORN D.M. (1966). Sedimentology, 6, p. 247-266. 